\title{
Rapid Assessment of Relative Density in Mixed-Species Stands of the Northeastern United States
}

\author{
M. J. Ducey and R. A. Knapp \\ Department of Natural Resources and the Environment, University of New Hampshire, 310 Nesmith Hall, Durham, NH 03824, USA \\ Correspondence should be addressed to M. J. Ducey, mjducey@cisunix.unh.edu
}

Received 22 June 2009; Accepted 1 December 2009

Academic Editor: Terry L. Sharik

Copyright ( $) 2010$ M. J. Ducey and R. A. Knapp. This is an open access article distributed under the Creative Commons Attribution License, which permits unrestricted use, distribution, and reproduction in any medium, provided the original work is properly cited.

\begin{abstract}
Basal area has shortcomings as a measure of stand density, but it is often preferred for operational assessments because it is easy to measure. Previous work has demonstrated that an additive version of Reineke's stand density index can be estimated by a simple tree count using a modified horizontal point sampling technique. We show that this technique can be extended further to estimate a mixed-species density measure that has been developed for complex stands in the northeastern United States, using wood specific gravity to harmonize the density contributions of different species. The sampling technique provides design-unbiased estimates of stand density from a weighted tree count, where the weights depend on specific gravity but not on diameter. Rounding the specific gravity values for different species in the calculation of estimates introduces a trivial amount of bias but streamlines the procedure for rapid use in the field.
\end{abstract}

\section{Introduction}

The ability to measure forest stand density is fundamental for both description and prescription in applied ecology including silviculture, forest health, and wildlife habitat management $[1,2]$. Basal area is the most commonly used density metric in practice, primarily because it is very fast and simple to measure in the field [3-5]. However, the basal area at which key ecological behaviors occur (such as crown closure, the onset of self-thinning, and asymptotic density) depends on the size of the trees in the stand, the species of those trees, and also potentially on the age and site quality of the stand. Other metrics, such as Reineke's [6] Stand Density Index (SDI) and related metrics such as those of Curtis [7] and Long and Daniel [8], offer improvements over basal area for monospecific stands. Reineke's [6] SDI is

$$
\mathrm{SDI}=N\left(\frac{D_{q}}{25}\right)^{1.6}
$$

where $N$ is number of trees per hectare, and $D_{q}$ is stand quadratic mean diameter. SDI has units of trees/ha. Zeide ([2, page 5]) writes that SDI is "still the best [metric] we have" for assessing stand density.
Recent research efforts have attempted to extend Reineke's [6] basic work to more complex stands than the even-aged, monospecific subjects of the original SDI. Long and Daniel [7] developed an additive version of SDI closely related to an index explored by Curtis [8]:

$$
\text { ASDI }=\Sigma_{i} N_{i}\left(\frac{D_{i}}{25}\right)^{1.6}
$$

where $N_{i}$ and $D_{i}$ are the number of trees per hectare and diameter of size classes of trees, and the summation is taken over an exhaustive, mutually-exclusive set of classes. (For continuous diameter distributions, the summation in (2) can be replaced by an integral and $N_{i}$ can be replaced by the product of $N$ and an appropriate probability density function; see $[9,10]$, e.g.) Several authors $[1,7,11]$ have suggested using ASDI for multicohort stands. More recently, Woodall et al. [12, 13], building on earlier mechanistic work [14], suggested that the maximum ASDI of mixed species stands could be estimated as a function of the mean specific gravity of the wood of trees on the plots and proposed a 
modified density measure. Ducey and Knapp [15], building on [12], suggested a relative density metric of the form

$$
\mathrm{RD}=\sum_{i j} N_{i j}\left(b_{0}+b_{1} \mathrm{SG}_{j}\right)\left(\frac{D_{i}}{25}\right)^{1.6},
$$

where $N_{i j}$ is the number of trees per hectare in the $i$ th diameter class of the $j$ th species, $b_{0}$ and $b_{1}$ are parameters to be estimated from plot data, and $\mathrm{SG}_{j}$ is the specific gravity of wood for the $j$ th species.

A challenge for any stand density metric more complex than basal area is that of obtaining a fast and simple estimate in the field. That challenge seems more and more difficult as stand density metrics such as that in (3) attempt to encompass stands that are more complex in diameter distribution and species mixture. Rapid field estimates are particularly valuable for diagnosis and description of stand conditions when a density metric will be used in situ in conjunction with expert opinion, and for controlling the marking of thinnings, shelterwoods, single-tree selection, and other partial harvests. Basal area would seem to have a distinct advantage in these situations, because a simple count of trees using a prism or other angle gauge, multiplied by the basal area factor of that gauge, provides a direct estimate of basal area per hectare $[16,17]$. However, a modified prism technique can provide estimates of ASDI through a simple count as well [18].

The goal of this study is to show how the modified prism technique [18] can be modified to provide direct estimates of the Ducey and Knapp [15] relative density for mixed species stands. We provide tables and instructions for implementing the approach and illustrate its application with data from a mixed-species stand in southeastern New Hampshire.

\section{Theory}

2.1. Mixed-Species Density Measure. Ducey and Knapp [15] proposed RD as a stand density metric for the mixed-species forests of New England and New York in the USA. They used data from the Forest Inventory and Analysis program of the U.S. Forest Service to estimate $b_{0}=0.00015$ and $b_{1}=$ 0.00218 , using specific gravity at $12 \%$ moisture content for each species. $\mathrm{RD}$ is a unitless fraction, scaled so that $\mathrm{RD}=0$ represents a completely empty stand, and $\mathrm{RD}=1$ represents a stocking level consistent with "normal" or A-line stocking using conventional stocking guides. For example, if $\mathrm{RD}=0.5$ for a particular stand, that stand has $50 \%$ of the stocking level implied by "normal" or A-line stocking.

Now, consider (3). It can be rewritten as

$$
\begin{aligned}
\mathrm{RD} & =\Sigma_{j}\left(b_{0}+b_{1} \mathrm{SG}_{j}\right)\left[\sum_{i} N_{i j}\left(\frac{D_{i}}{25}\right)^{1.6}\right] \\
& =\Sigma_{j}\left(b_{0}+b_{1} \mathrm{SG}_{j}\right) \mathrm{ASDI}_{j}
\end{aligned}
$$

which makes clear that RD is simply a weighted form of ASDI, where the weights for different species are determined by their specific gravity.
Ducey and Valentine [18] developed a technique analogous to sampling for basal area with a prism, in which tree count times a factor gives ASDI. We will show that it is possible to modify that technique to give $\mathrm{RD}$ as a sum of weights for the tallied trees. First, we review the modified prism technique for ASDI.

2.2. Direct Sampling Technique. Recall that in ordinary horizontal point sampling (HPS) with a prism, relascope, or other angle gauge, each tallied tree represents the same amount of basal area per hectare [16]. That quantity is called the basal area factor or BAF, and that quantity is constant for a given gauge because the area of the inclusion zone (the area within which a specific tree will be tallied) is directly proportional to the basal area of the individual tree. This result follows from the geometry of the gauge: the radius of the inclusion zone (also called the limiting distance) equals the gauge constant (or ratio of length to width) times the diameter of the tree. Mathematical proofs are provided by [19], while [20] provides a thorough discussion of HPS in its many applications.

If the inclusion zone radius could be made proportional to $D^{0.8}$, rather than proportional to $D$, then inclusion zone area would be proportional to $D^{1.6}$ and each tallied tree would represent a constant amount of ASDI [18]. This quantity is called the stand density factor (SDF), by analogy to the BAF of ordinary HPS. Recall that ASDI has units of trees/ha; so SDF also has units of trees/ha. If the method of [18] is used, and if $m$ trees are tallied at $n$ points, then the estimate of ASDI is simply

$$
\mathrm{ASDI}=\left(\frac{m}{n}\right) \mathrm{SDF}
$$

If the SDF is chosen with reasonable care, then the limiting distances for a given SDF are very close to those for the BAF that would ordinarily be used in similar stand conditions [18] (Figure 1). The slight departure, depending only on tree diameter, could easily be adjusted in the field by "pushing the point" or "pulling the point." Pushing the point [21] consists of holding the prism not directly over the sample point but extended toward the tree of interest. In ordinary HPS pushing the point is a common field error, and it creates biased estimates. Pulling the point consists of holding the prism back and sighting across the sample point to determine whether a tree should be tallied. A simple table of the distance to push or pull the point, in relation to $D$ for individual trees, is adequate to provide a sample with a constant SDF [18]. In practice, it is not usually necessary to know the exact $D$ of an individual tree to determine whether it should be included in the sample. Because the degree of push or pull changes slowly with $D$, an initial ocular estimate is usually sufficient. $D$ should be measured on borderline trees, and if an estimate of ASDI is desired for different diameter classes, then $D$ can be measured on the tallied trees as well.

Now suppose that we wish to modify the technique to estimate RD, building on (4). Let $m_{j}$ be the number of trees 
of the $j$ th species tallied, using $n$ sample points as before. Then

$$
\operatorname{ASDI}_{j}=\left(\frac{m_{j}}{n}\right) \mathrm{SDF}
$$

provides an estimate of the ASDI of species $j$, and

$$
\left(b_{0}+b_{1} \mathrm{SG}_{j}\right) \mathrm{ASDI}_{j}=\left(b_{0}+b_{1} \mathrm{SG}_{j}\right)\left(\frac{m_{j}}{n}\right) \mathrm{SDF}
$$

provides a natural estimator of the summand in (4). Rearranging slightly, and substituting, we have

$$
\mathrm{RD}=\Sigma_{j}\left(\frac{m_{j}}{n}\right)\left[\left(b_{0}+b_{1} \mathrm{SG}_{j}\right) \mathrm{SDF}\right]
$$

as a natural estimator for $\mathrm{RD}$. In other words, $\mathrm{RD}$ can be estimated as a weighted tree count, in which each tree at a single sample point represents $\left[\left(b_{0}+b_{1} \mathrm{SG}_{j}\right) \mathrm{SDF}\right]$ units of RD. Recall that RD is a unitless fraction; therefore the weight or contribution of an individual tree $\left[\left(b_{0}+b_{1} \mathrm{SG}_{j}\right) \mathrm{SDF}\right]$ is also a unitless fraction. Proofs of unbiasedness of (5), (6), and (8) are given in the appendix.

In practice, if "exact" (or at least, unrounded) values of $\mathrm{SG}_{j}$ are used, the quantity $\left[\left(b_{0}+b_{1} \mathrm{SG}_{j}\right) \mathrm{SDF}\right]$ will likely be a cumbersome fraction. This is not a problem if, for example, field computers are used to provide nearly instantaneous feedback on sample results. However, for the cruiser or timber marker who desires a simple, rapid field procedure, it may be more convenient to group species and use an approximate value so that $\left[\left(b_{0}+b_{1} \mathrm{SG}_{j}\right) \mathrm{SDF}\right]$ is always a nearly round percentage. This requires advance tabulation of species into groups, which we undertake hereinafter. Furthermore, it does introduce a small amount of bias due to rounding error. As we show, this is likely to be negligible for samples taken at typical operational intensities.

\section{Application}

One of the first steps in direct sampling for ASDI is to choose a BAF and corresponding SDF [18]. In the northeastern United States, a BAF of $2.3 \mathrm{~m}^{2} / \mathrm{h}$ a is a common choice but can lead to nondetection errors; so a larger BAF is desirable $[22,23]$. Prisms with a BAF of $4 \mathrm{~m}^{2} /$ ha are widely available and fall within the range recommended for the region [24]. For a given BAF, the SDF should be chosen such that the limiting distances are similar. This allows the push or pull to be done quickly and accurately. A good match to BAF $4 \mathrm{~m}^{2} / \mathrm{ha}$ is an SDF of 50 trees/ha: the limiting distances differ by less than $2 \mathrm{~m}$ over a broad range of $\mathrm{DBH}$, and "pulling the point" is only necessary for rare trees with $\mathrm{DBH}>85 \mathrm{~cm}$. The limiting distances and push/pull for an SDF 50 using a BAF 4 are shown in Table 1.

Ducey and Knapp [15] tabulate SG for all the species found in New York and New England in the USFS FIA database. However, for fast application in the field it is useful to tabulate rounded values of $\left[\left(b_{0}+b_{1} \mathrm{SG}_{j}\right) \mathrm{SDF}\right]$ as weights. This is done in Table 2, with weights multiplied by 100 so that they reflect percents rather than fractions.
Armed with Tables 1 and 2, it is straightforward to conduct field sampling and to calculate estimates. For example, suppose that we have used our prism and Table 1 to determine which trees to sample at a single point. We tallied 7 trees: 3 Betula papyrifera, 1 Picea rubens, 2 Abies balsamea, and 1 Fagus grandifolia. We can immediately determine that the ASDI at this point is $7 \times 50=350$, and RD is $3 \times 7+1 \times$ $5+2 \times 5+1 \times 8=44 \%$, or 0.44 .

\section{Field Demonstration}

To illustrate the calculations associated with the method, we conducted sampling in a 4.3 ha mixed-species stand located in Durham, NH. 12 sample points were located systematically on a $60 \mathrm{~m}$ by $60 \mathrm{~m}$ grid. We used a BAF $4 \mathrm{~m}^{2} / \mathrm{ha}$ prism, and the push-pull values from Table 1 , to obtain a sample of trees with an SDF of 50 trees/ha. Both the exact weights as calculated from the specific gravities tabulated in [15], and rounded weights from Table 2, were used to estimate $\mathrm{RD}$ for comparison.

A total of 133 trees were tallied on the 12 plots. Of these, 49 were Tsuga canadensis, 33 were Pinus strobus, 31 were Acer rubrum, 10 were Quercus rubra, 5 were Fagus grandifolia, 4 were Betula allegheniensis, and 1 was Quercus alba. $\mathrm{RD}$ as calculated using the exact weights was $65.6 \%$, with a standard error of $7.6 \%$; the coefficient of variation of the sample points was $40 \%$. RD as calculated using the rounded weights was $63.3 \%$, with a standard error of $7.7 \%$; the coefficient of variation of the sample points was $42 \%$. In this stand at least, the difference caused by rounding the weights is trivial in comparison with the sampling variability of $\mathrm{RD}$.

\section{Discussion and Conclusions}

Metrics of stand density can be viewed in two ways: as hypotheses about or models of stand dynamics and as operational aids to silviculture. From the first perspective, stand basal area has long been rejected. Even in singlespecies, single-cohort stands, the inadequacy of basal area for comparing density in stands of different tree size and species was known long before Reineke's [6] work and provided much of the impetus for his efforts. Even in those stands, Reineke's work represents a simplification, obscuring potentially important interspecific differences in allometry and growth [25]. Extension of Reineke's ideas to multicohort stands and other stands with complex structure has been an important area of recent work [7, 26-28]. While empirical tests of those efforts in comparison to previous measures have been relatively rare $[9,29]$, some progress has been made at least in understanding how one might approach the design of experiments [10].

A variety of studies have explored adapations of SDI to mixed-species stands [12, 13, 30-36]. However, the Ducey and Knapp [15] formulation has two properties that are both required for the straightforward use of the sampling method developed here. The first property is additivity [9]. An index is said to be additive if, for two stand components $A$ and $B$, the density of $A$ and $B$ considered together equals the density 


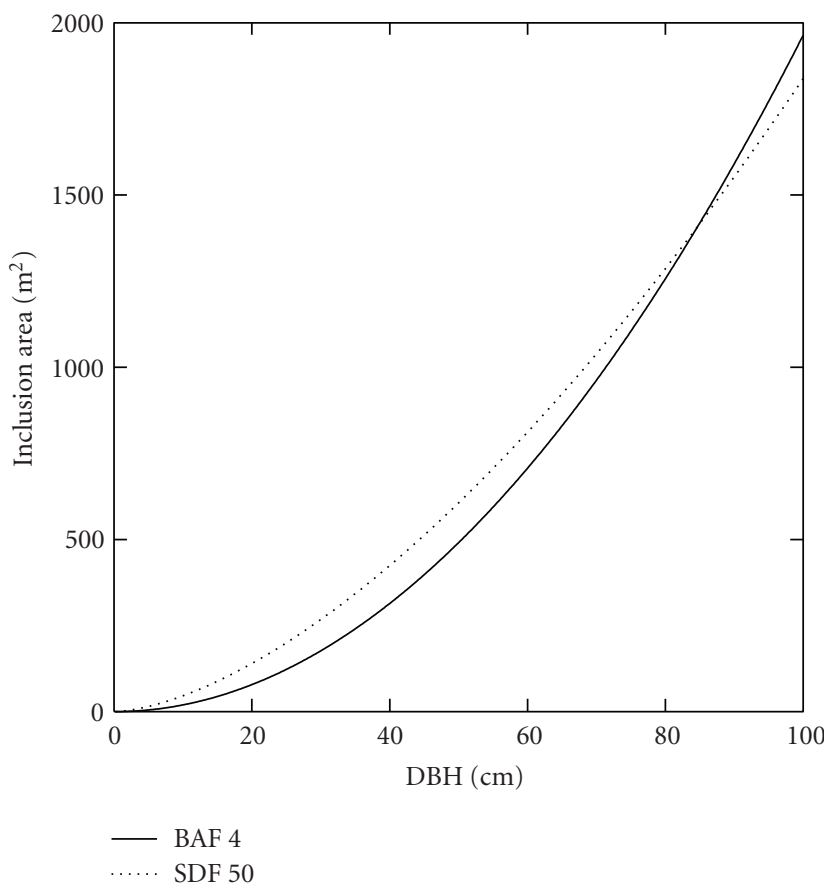

(a)

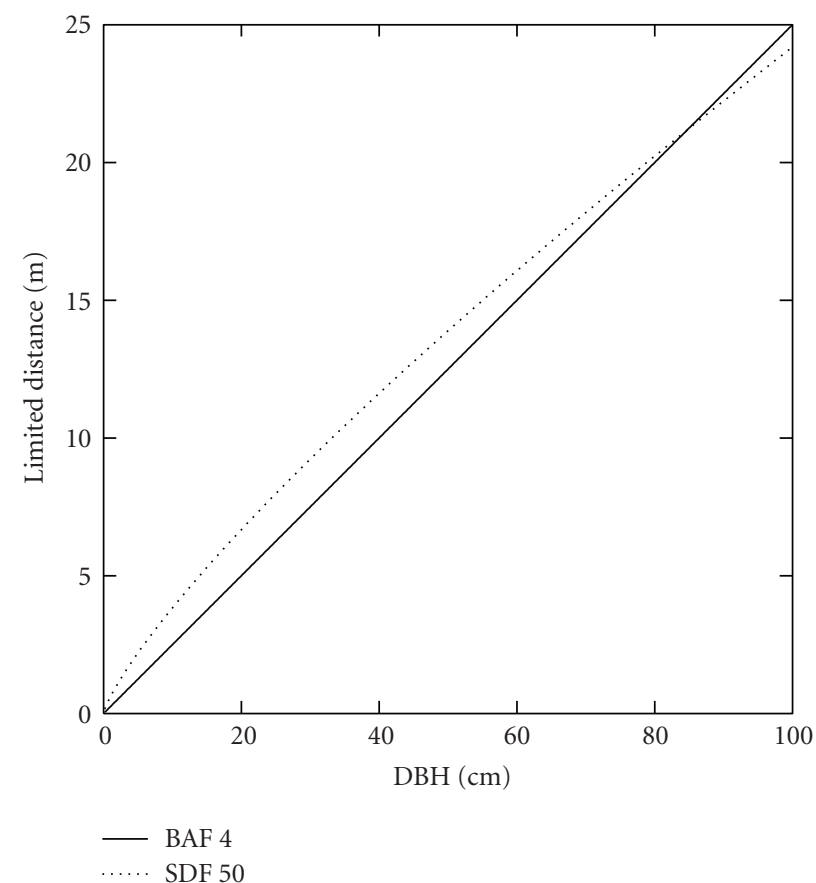

(b)

FIGURE 1: Area of the inclusion zone and limiting distance (or inclusion zone radius), for ordinary HPS with a BAF $4 \mathrm{~m}^{2} / \mathrm{ha}$ gauge and direct sampling for ASDI with a stand density factor of 50.

TABLE 1: Critical distances and required "push" for sampling with a stand density factor (SDF) of 50, using a basal area factor (BAF) $4 \mathrm{~m}^{2} / \mathrm{ha}$ prism. When the "push" is shown as negative, the prism must be pulled back across the point.

\begin{tabular}{|c|c|c|c|}
\hline $\mathrm{DBH}, \mathrm{cm}$ & $\begin{array}{l}\text { BAF }=4 \text { Critical } \\
\text { Distance, } \mathrm{m}\end{array}$ & $\begin{array}{l}\mathrm{SDF}=50 \\
\text { Critical } \\
\text { Distance, m }\end{array}$ & Required Push, m \\
\hline 5 & 1.25 & 2.20 & 0.95 \\
\hline 10 & 2.50 & 3.83 & 1.33 \\
\hline 15 & 3.75 & 5.30 & 1.55 \\
\hline 20 & 5.00 & 6.67 & 1.67 \\
\hline 25 & 6.25 & 7.98 & 1.73 \\
\hline 30 & 7.50 & 9.23 & 1.73 \\
\hline 35 & 8.75 & 10.44 & 1.69 \\
\hline 40 & 10.00 & 11.62 & 1.62 \\
\hline 45 & 11.25 & 12.77 & 1.52 \\
\hline 50 & 12.50 & 13.89 & 1.39 \\
\hline 55 & 13.75 & 14.99 & 1.24 \\
\hline 60 & 15.00 & 16.07 & 1.07 \\
\hline 65 & 16.25 & 17.14 & 0.89 \\
\hline 70 & 17.50 & 18.18 & 0.68 \\
\hline 75 & 18.75 & 19.21 & 0.46 \\
\hline 80 & 20.00 & 20.23 & 0.23 \\
\hline 85 & 21.25 & 21.24 & -0.01 \\
\hline 90 & 22.50 & 22.23 & -0.27 \\
\hline 95 & 23.75 & 23.21 & -0.54 \\
\hline 100 & 25.00 & 24.19 & -0.81 \\
\hline
\end{tabular}


TABLE 2: Rounded weights (values of $\left.100 \times\left[\left(b_{0}+b_{1} \mathrm{SG}_{j}\right) \mathrm{SDF}\right]\right)$ for common species in New York and New England, using an SDF of 50.

\begin{tabular}{|c|c|c|}
\hline Species & Specific Gravity Range & Weight \\
\hline Maclura pomifera & 0.84 & 10 \\
\hline $\begin{array}{l}\text { Carpinus caroliniana, Carya spp. } \\
\text { (except laciniosa), Cornus florida, } \\
\text { Ostrya virginiana, Quercus bicolor }\end{array}$ & $0.72-0.78$ & 9 \\
\hline $\begin{array}{l}\text { Acer platanoides, Acer saccharum, } \\
\text { Betula allegheniensis, Betula lenta, } \\
\text { Betula nigra, Carya laciniosa, Crataegus } \\
\text { spp., Fagus grandifolia, Gleditsia } \\
\text { tricanthos, Malus spp., Quercus alba } \\
\text { and the other white oaks (except } \\
\text { bicolor), Quercus rubra and the other } \\
\text { red oaks (except velutina and ilicifolia), } \\
\text { Robinia pseudoacacia, Ulmus thomasii }\end{array}$ & $0.62-0.69$ & 8 \\
\hline $\begin{array}{l}\text { Acer rubrum, Amelanchier spp., Betula } \\
\text { papyrifera, Celtis occidentalis, Fraxinus } \\
\text { spp. (except nigra), Juglans nigra, Larix } \\
\text { laricina, Quercus velutina, Quercus } \\
\text { ilicifolia, Ulmus rubra }\end{array}$ & $0.53-0.61$ & 7 \\
\hline $\begin{array}{l}\text { Acer montanum, Acer negundo, Acer } \\
\text { pennsylvanicum, Acer saccharinum, } \\
\text { Betula populifolia, Fraxinus nigra, } \\
\text { Juniperus virginiana, Nyssa sylvatica, } \\
\text { Platanus occidentalis, Picea mariana, } \\
\text { Pinus resinosa, Pinus rigida, Pinus } \\
\text { sylvestris, Prunus spp. (except } \\
\text { pennsylvanica and virginiana), } \\
\text { Sassafras albidum, Sorbus americana, } \\
\text { Ulmus americana }\end{array}$ & $0.44-0.52$ & 6 \\
\hline $\begin{array}{l}\text { Abies balsamea, Castanea dentata, } \\
\text { Juglans cinerea, Liriodendron tulipifera, } \\
\text { Picea spp. (except mariana), Pinus } \\
\text { (except rigida and sylvestris), Populus } \\
\text { spp. (except balsamifera), Prunus } \\
\text { pennsylvanica, Prunus virginiana, Salix } \\
\text { spp., Tilia americana, Tsuga canadensis }\end{array}$ & $0.35-0.43$ & 5 \\
\hline $\begin{array}{l}\text { Chamaecyparis thyoides, Populus } \\
\text { balsamifera, Thuja occidentalis }\end{array}$ & $0.31-0.34$ & 4 \\
\hline
\end{tabular}

of $A$ considered alone, plus the density of $B$ considered alone. Additivity is required for unbiased estimation of any stand density metric using traditional methods (such as fixed-area plot sampling or HPS, or any method that can be identified as using a Horvitz-Thompson [37] estimator) $[38,39]$. Among previous mixed-species indices, only that of Stout and colleagues $[31,32]$ is additive; that of Woodall et al. $[12,13]$ meets the criterion of separability but not additivity [9]. By analogy with site index curves, we may also say that a density measure is anamorphic if, for two different species, the density contribution of an individual of species $X$ divided by that of an individual of the same $D$ but of species $Y$ is a constant that does not depend on $D$. The density measure of Stout and colleagues $[12,13]$ is not anamorphic. If a density measure is not anamorphic, then a different "push" or "pull" would be required for each species or species group. Thus, the Ducey and Knapp [15] formulation has certain practical advantages from a measurement standpoint.
We caution, however, that simplicity and practicality may be advantageous but do not imply biological correctness [9]. Both additivity and anamorphism are likely incorrect from a strictly biological and mechanistic standpoint [9, $25,40]$. On the other hand, detecting departures from additivity and anamorphism implies the availability of an additive, anamorphic measurement from which to construct a baseline.

At its heart, a stand density index is a model, hypothesis, or conjecture about the relationship between measurable quantities and ecological behaviors. Statistician G.E.P. Box [41, page 2] wrote "Models, of course, are never true, but fortunately it is only necessary that they be useful." The durability of basal area as a practical measure of stand density points to the importance of rapid, simple measurement as a component of utility. Box [42, page 792] also wrote "Since all models are wrong the scientist must be alert to what is importantly wrong. It is inappropriate to be concerned about 
mice when there are tigers abroad." One tiger abroad in stand density measurement is sampling variability. Fast, repeatable measurement with relatively low sampling variability has been a reality for basal area since the seminal work of Bitterlich [16] on HPS. However, the recent generalization of HPS for ASDI [18], and the approach for RD as explored here, may close the gap somewhat.

In theory, the modified HPS approach [18] and this method could be used as a general sampling approach, if tree diameters are measured. However, the need to push (or pull) the point does open the door to field errors. The results from ordinary HPS should be more precise and less prone to operator error, even when a final variable of interest is RD. Rather, the strength of the approach we present here is for near-instantaneous estimation of stand density in three primary situations.

(1) The first situation is to allow quick assessment and description of stand conditions. Fast calculation of RD would allow more effective coupling between quantitative measurement and subjective, expert opinion [18]. Density indices and related diagrams are best viewed as complementary to qualitative silvicultural expertise [43]; a rapid measurement technique can make quantitative information available to the forester or ecologist on-site.

(2) The second one is to enable control of residual density while marking partial harvests such as thinnings and shelterwoods.

(3) The third one is to provide a simple point density estimate for use in ecological studies that would be available immediately for stratification or subsampling purposes.

\section{Appendix}

Equation [7] provides an estimating equation for $\mathrm{RD}$ when trees are sampled using the modified point sampling technique. In this appendix, we present a formal proof of design-unbiasedness for this estimating equation.

Suppose that we are interested in the population of trees occurring in a tract of area $A$. Let the trees be indexed by $k=1, \ldots, K$, where $K$ is the total number of trees. $K$ is fixed but unknown, as are the diameters $D_{k}$ of the trees at the outset of sampling. Without loss of generality, let us locate a single point at random and with uniform density within the tract. This point will be our sample point, and from it we will include all trees located at a distance no greater than $c D^{0.8}$, where $c$ is a constant chosen in advance. Denote the inclusion area of the $k$ th tree by $a_{k} ; a_{k}$ is the area where the sample point may fall and the $k$ th tree will be included. From basic geometry we have

$$
a_{k}=\pi\left(c D^{0.8}\right)^{2}=\pi c^{2} D_{k}^{1.6}
$$

and the probability $p_{k}$ that the $k$ th tree will be included in the sample (ignoring boundary slopover, which can easily be corrected using the walkthrough method [44]) is

$$
p_{k}=\frac{a_{k}}{A}
$$

We can rewrite (2) as

$$
\operatorname{ASDI}=\left(\frac{1}{A}\right) \Sigma_{k}\left(\frac{D_{k}}{25}\right)^{1.6} .
$$

Now let $d_{k}$ be an indicator variable taking the value 1 if the $k$ th tree is included in the sample, and 0 otherwise; the expectation is $E\left[d_{k}\right]=p_{k}$. The total number of trees included in the sample is

$$
m=\Sigma_{k} d_{k}
$$

and its expectation is

$$
E[m]=E\left[\Sigma_{k} d_{k}\right]=\Sigma_{k} p_{k}=\left(\frac{\pi c^{2}}{A}\right) \Sigma_{k} D_{k}^{1.6}=\left[\pi c^{2} 25^{-1.6}\right] \mathrm{ASDI}
$$

from which it follows directly that if $\mathrm{SDF}=25^{1.6} /\left(\pi c^{2}\right)$, then $\mathrm{mSDF}$ is a design-unbiased estimator of ASDI, since

$$
E[m \mathrm{SDF}]=\operatorname{SDF} E[m]=\mathrm{ASDI},
$$

and if we collect data at $\mathrm{n}$ such sample points, the sample mean $(m / n$ SDF $)$ will also provide a design-unbiased estimate. This proves the unbiasedness of the estimator in (5). Furthermore, if we restrict the population to consist only of trees of species $j$ and replace $m$ with $m_{j}$ and ASDI with ASDI in the above equations, the equations still hold; this proves the unbiasedness of the estimator in (6).

In general, if there is an attribute $y_{k}$ associated with the $k$ th tree, an estimator of the form

$$
Y=\frac{\Sigma_{k} d_{k} y_{k}}{p_{k}}
$$

is a Horvitz-Thompson [37] estimator and provides a design-unbiased estimate of the population total $\Sigma_{k} y_{k}$. Now, consider (4), rewritten as a population total:

$$
\mathrm{RD}=\left(\frac{1}{A}\right)\left(b_{0}+b_{1} \mathrm{SG}_{k}\right)\left(\frac{D_{k}}{25}\right)^{1.6}
$$

where $\mathrm{SG}_{k}$ is the specific gravity of the $k$ th tree, so that

$$
y_{k}=\left(\frac{1}{A}\right)\left(b_{0}+b_{1} \mathrm{SG}_{k}\right)\left(\frac{D_{k}}{25}\right)^{1.6} \text {. }
$$

Now, if we substitute this into the basic Horvitz-Thompson estimator, we obtain

$$
\begin{aligned}
Y & =\frac{\sum_{k} d_{k}\left[(1 / A)\left(b_{0}+b_{1} \mathrm{SG}_{k}\right)\left(D_{k} / 25\right)^{1.6}\right]}{p_{k}} \\
& =\Sigma_{k} d_{k}\left[\left(\frac{1}{A}\right)\left(b_{0}+b_{1} \mathrm{SG}_{k}\right)\left(\frac{D_{k}}{25}\right)^{1.6}\right] /\left[\pi c^{2} D_{k}^{1.6} / A\right] \\
& =\Sigma_{k} d_{k}\left[\frac{\left(b_{0}+b_{1} \mathrm{SG}_{k}\right) 25^{1.6}}{\pi c^{2}}\right] \\
& =\operatorname{SDF} \Sigma_{k} d_{k}\left(b_{0}+b_{1} \mathrm{SG}_{k}\right) .
\end{aligned}
$$


Now, recognizing that all trees of the $j$ th species have the same specific gravity for our purposes, and letting $\mathrm{SG}_{j}$ represent the specific gravity of the $j$ th species as before, we see that

$$
Y=\Sigma_{j} m_{j}\left[\left(b_{0}+b_{1} \mathrm{SG}_{j}\right) \mathrm{SDF}\right]
$$

is the design-unbiased Horvitz-Thompson estimator associated with a single sample point, and the mean of several sample points is identical to (8), which must also be designunbiased.

\section{Acknowledgments}

Colleen Didas assisted with the field work. Development of the relative density index was supported under a grant from the National Science Foundation, "Collaborative Research: The northeastern carbon sink: enhanced growth, regrowth, or both?" to M. J. Ducey. This paper is a scientific contribution of the New Hampshire Agricultural Experiment Station.

\section{References}

[1] J. N. Long, "A practical approach to density management," Forestry Chronicle, vol. 61, no. 1, pp. 23-27, 1985.

[2] B. Zeide, "How to measure stand density," Trees, vol. 19, no. 1, pp. 1-14, 2005.

[3] S. H. Spurr, Forest Inventory, Ronald Press, New York, NY, USA, 1952.

[4] C. A. Bickford, F. S. Baker, and F. G. Wilson, "Stocking, normality, and measurement of stand density," Journal of Forestry, vol. 55, no. 2, pp. 99-104, 1957.

[5] T. E. Avery and H. E. Burkhart, Forest Measurements, John Wiley \& Sons, New York, NY, USA, 5th edition, 2002.

[6] L. H. Reineke, "Perfecting a stand-density index for even-aged forests," Journal of Agricultural Research, vol. 46, no. 7, pp. 627-638, 1933.

[7] R. O. Curtis, "A tree area power function and related density measures for Douglas-fir," Forest Science, vol. 17, no. 2, pp. 146-159, 1971.

[8] J. N. Long and T. W. Daniel, "Assessment of growing stock in uneven-aged stands," Western Journal of Applied Forestry, vol. 5, no. 3, pp. 93-96, 1990.

[9] M. J. Ducey and B. C. Larson, "Is there a correct stand density index? An alternate interpretation," Western Journal of Applied Forestry, vol. 18, no. 3, pp. 179-184, 2003.

[10] M. J. Ducey, "The ratio of additive and traditional stand density indices," Western Journal of Applied Forestry, vol. 24, no. 1, pp. 5-10, 2009.

[11] C. E. Fiedler and J. E. Cully, "A silvicultural approach to develop Mexican spotted owl habitat in Southwest forests," Western Journal of Applied Forestry, vol. 10, no. 4, pp. 144-148, 1995.

[12] C. W. Woodall, P. D. Miles, and J. S. Vissage, "Determining maximum stand density index in mixed species stands for strategic-scale stocking assessments," Forest Ecology and Management, vol. 216, no. 1-3, pp. 367-377, 2005.

[13] C. W. Woodall, C. H. Perry, and P. D. Miles, "The relative density of forests in the United States," Forest Ecology and Management, vol. 226, no. 1-3, pp. 368-372, 2006.

[14] T. J. Dean and V. C. Baldwin Jr., "The relationship between Reineke's stand-density index and physical stem mechanics,"
Forest Ecology and Management, vol. 81, no. 1-3, pp. 25-34, 1996.

[15] M. J. Ducey and R. A. Knapp, "Utilizing quantile regression to develop a stand density index for mixed species stands in the northeastern United States," Canadian Journal of Forest Research. In review.

[16] W. Bitterlich, "Die Winkelzählprobe," Allgemeine Forst- und Holzwirtschaftliche Zeitung, vol. 59, no. 1-2, pp. 4-5, 1948.

[17] L. R. Grosenbaugh, "Plotless timber estimates-new, fast, easy," Journal of Forestry, vol. 50, no. 1, pp. 32-37, 1952.

[18] M. J. Ducey and H. T. Valentine, "Direct sampling for stand density index," Western Journal of Applied Forestry, vol. 23, no. 2, pp. 78-82, 2008.

[19] L. R. Grosenbaugh, "Point sampling and line sampling: probability theory, geometric implications, synthesis," Occasional Paper 160, USDA Forest Service, Southern Forest Experiment Station, Asheville, NC, USA, 1957.

[20] W. Bitterlich, The Relascope Idea: Relative Measurements in Forestry, Commonwealth Agricultural Bureaux, Farnham Royal, Slough, UK, 1984.

[21] R. G. Oderwald and T. G. Gregoire, "Overstated volumes from 'pushing the point,"' Southern Journal of Applied Forestry, vol. 19, no. 4, pp. 162-165, 1995.

[22] L. C. Wensel, J. Levitan, and K. Barber, "Selection of basal area factor in point sampling," Journal of Forestry, vol. 78, no. 2, pp. 83-84, 1980.

[23] H. V. Wiant Jr., D. O. Yandle, and R. Andreas, "Is BAF 10 a good choice for point sampling?" Northern Journal of Applied Forestry, vol. 1, no. 2, pp. 23-25, 1984.

[24] M. J. Ducey, "Pre-cruise planning," in Workshop Proceedings: Forest Measurements for Natural Resource Professionals. II. Getting the Most from Your Cruise, University of New Hampshire Cooperative Extension, Durham, NH, USA, 2001.

[25] H. Pretzsch and P. Biber, "A re-evaluation of Reineke's rule and stand density index," Forest Science, vol. 51, no. 4, pp. 304-320, 2005.

[26] J. N. Long, "Using stand density index to regulate stocking in uneven-aged stands," in Uneven-Aged ManagementOpportunities, Constraints, and Methodologies, K. O'Hara, Ed., vol. 56, pp. 110-122, Montana Forest and Conservation Experiment Station, 1995.

[27] J. N. Long, "A technique for the control of stocking in twostoried stands," Western Journal of Applied Forestry, vol. 11, no. 2, pp. 59-61, 1996.

[28] J. D. Shaw, "Application of stand density index to irregularly structured stands," Western Journal of Applied Forestry, vol. 15, no. 1, pp. 40-42, 2000.

[29] C. W. Woodall, C. E. Fiedler, and K. S. Milner, "Stand density index in uneven-aged ponderosa pine stands," Canadian Journal of Forest Research, vol. 33, no. 1, pp. 96-100, 2003.

[30] S. L. Stout and R. D. Nyland, "Role of species composition in relative density measurement in Allegheny hardwoods," Canadian Journal of Forest Research, vol. 16, no. 3, pp. 574579, 1986.

[31] S. L. Stout, D. A. Marquis, and R. L. Ernst, "A relative density measure for mixed-species stands," Journal of Forestry, vol. 85, no. 7, pp. 45-47, 1987.

[32] K. J. Puettmann, D. E. Hibbs, and D. W. Hann, "The dynamics of mixed stands of Alnus rubra and Pseudotsuga menziesii: extension of size-density analysis to species mixture," Journal of Ecology, vol. 80, no. 3, pp. 449-458, 1992.

[33] K. J. Puettmann, D. W. Hann, and D. E. Hibbs, "Evaluation of the size-density relationships for pure red alder and Douglasfir stands," Forest Science, vol. 39, no. 1, pp. 7-27, 1993. 
[34] P. H. Cochran, J. M. Geist, D. L. Clemens, R. R. Clausnitzer, and D. C. Powell, "Suggested stocking levels for forest stands in northeastern Oregon and southeastern Washington," Res. Note PNW-RN-513, U.S. Department of Agriculture Forest Service, Pacific Northwest Research Station, Portland, Ore, USA, 1994.

[35] J. M. Torres-Rojo and A. Martinez, "Relative stand density index for mixed even-aged stands," Agrociencia, vol. 4, pp. 497-507, 2000.

[36] R. A. Williams, "Use of stand density index as an alternative to stocking percent in upland hardwoods," Northern Journal of Applied Forestry, vol. 20, no. 3, pp. 137-142, 2003.

[37] D. G. Horvitz and D. J. Thompson, "A generalization of sampling without replacement from a finite universe," Journal of the American Statistical Association, vol. 47, no. 260, pp. 8996, 1952.

[38] M. J. Ducey and B. C. Larson, "Thinning decisions using stand density indices: the influence of uncertainty," Western Journal of Applied Forestry, vol. 12, no. 3, pp. 89-92, 1997.

[39] M. J. Ducey and B. C. Larson, "Accounting for bias and uncertainty in nonlinear stand density indices," Forest Science, vol. 45, no. 3, pp. 452-457, 1999.

[40] H. Pretzsch, "Species-specific allometric scaling under selfthinning: evidence from long-term plots in forest stands," Oecologia, vol. 146, no. 4, pp. 572-583, 2006.

[41] G. E. P. Box, "Some problems of statistics and everyday life," Journal of the American Statistical Association, vol. 74, no. 365, pp. 1-4, 1972.

[42] G. E. P. Box, "Science and statistics," Journal of the American Statistical Association, vol. 71, no. 356, pp. 791-799, 1976.

[43] J. N. Long and J. D. Shaw, "A density management diagram for even-aged ponderosa pine stands," Western Journal of Applied Forestry, vol. 20, no. 4, pp. 205-215, 2005.

[44] M. J. Ducey, J. H. Gove, and H. T. Valentine, "A walkthrough solution to the boundary overlap problem," Forest Science, vol. 50, no. 4, pp. 427-435, 2004. 

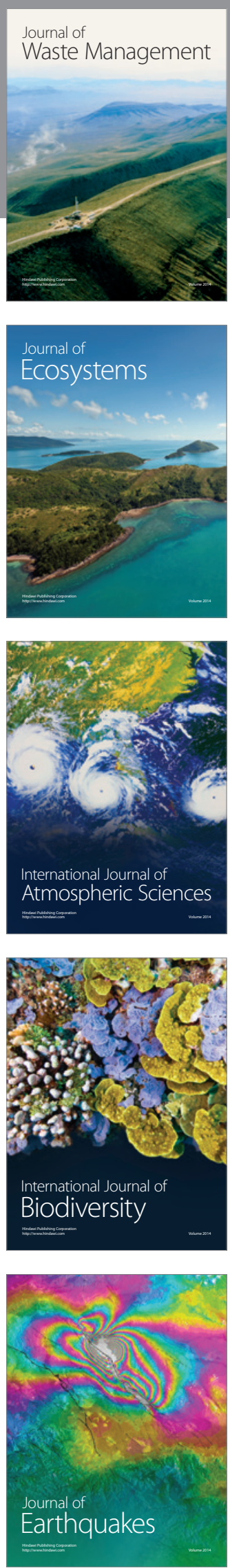
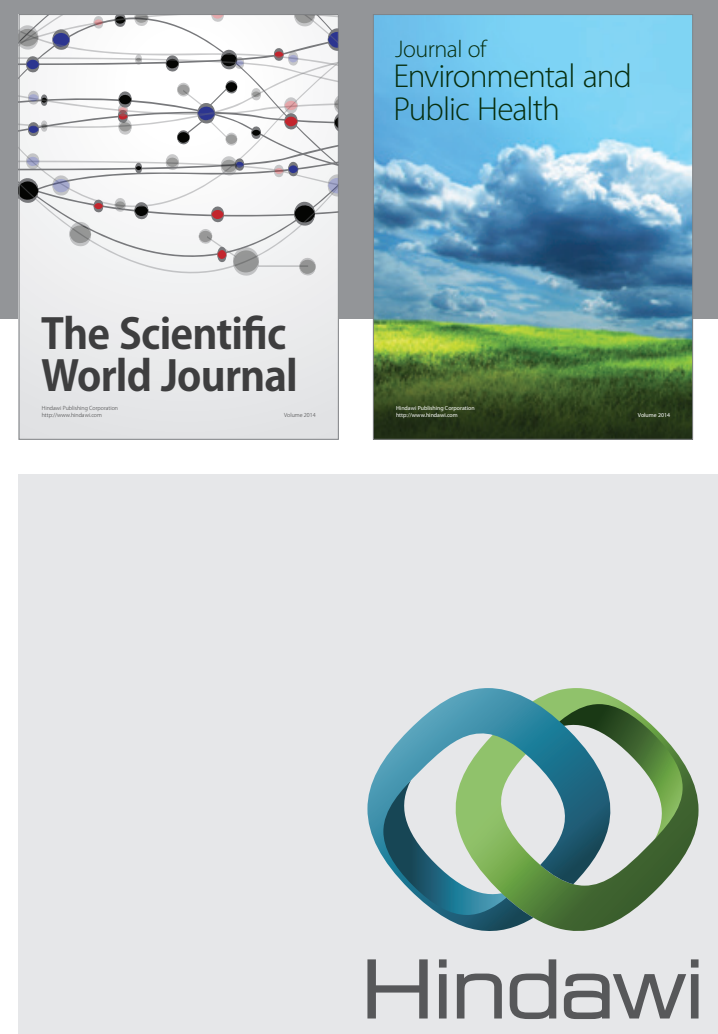

Submit your manuscripts at

http://www.hindawi.com
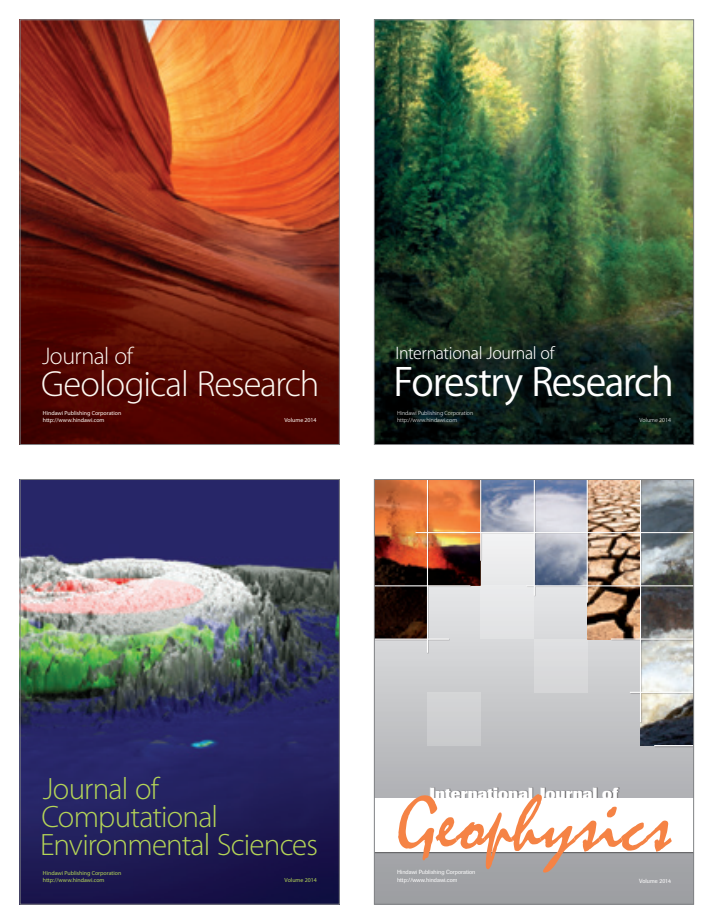
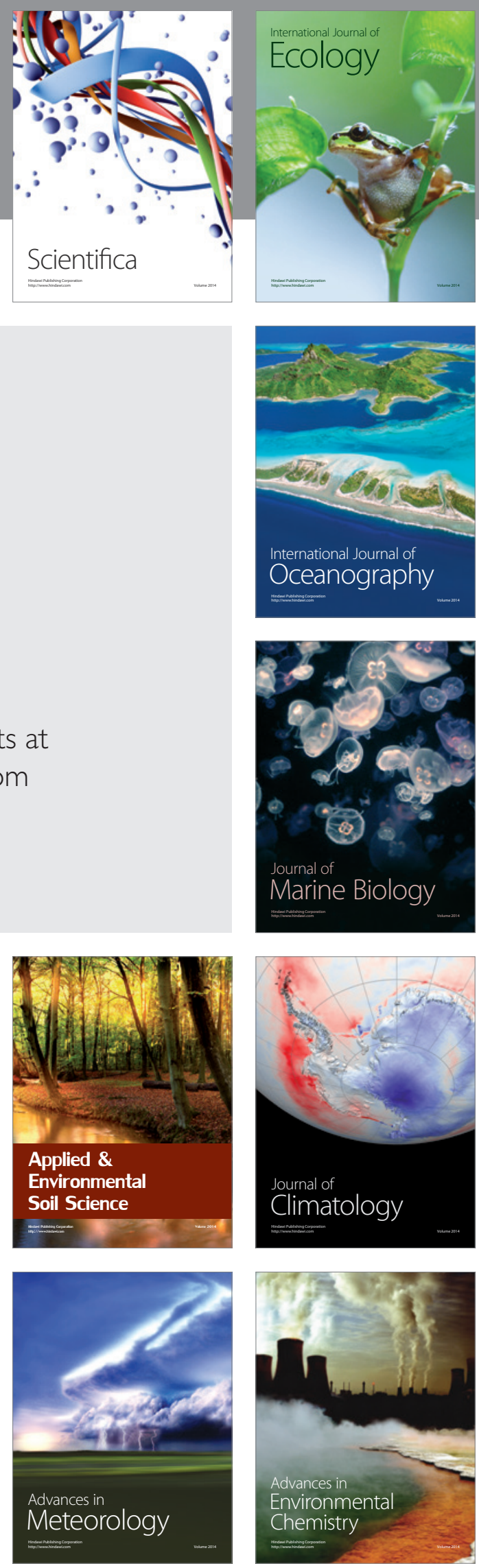